\title{
Das lágrimas às palavras: manifestações do pathos segundo a medicina da alma moderna*
}

Paulo José Carvalho da Silva Melina Borges Rosa Cavalcante

\begin{abstract}
Este artigo propõe analisar discursos da primeira modernidade sobre a fonte, natureza e finalidade das lágrimas. Em primeiro lugar, examina-se a noção de olhar para chegar à origem das paixões. Então, aborda-se as relações entre o chorar e a afetividade para, finalmente, discutir a relação das lágrimas e as palavras.
\end{abstract}

Palavras-chave: Lágrimas, pathos, palavras, medicina da alma

* Pesquisa realizada com apoio da Fundação de Apoio à Pesquisa do Estado de São Paulo Fapesp (São Paulo, SP, Brasil). 


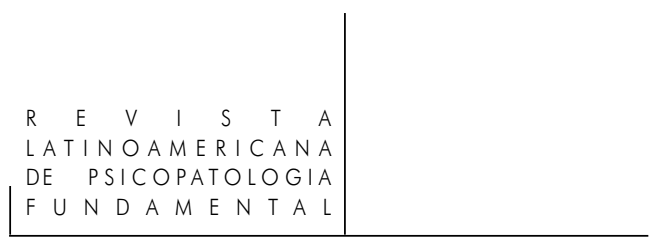

Em seu discurso Lágrimas de Heráclito defendidas em Roma pelo Padre Antônio Vieira contra o riso de Demócrito, proferido em Roma, na Real Academia da rainha Cristina da Suécia, em 1674, o célebre padre Antônio Vieira (1608-1696) afirma: "Não residem as lágrimas só nos olhos, que vêem os objetos, mas nos mesmos objetos que são vistos; ali está a fonte, aqui está o rio; ali nascem as lágrimas, aqui correm” (Vieira, 1674, p. 141).

No Sermão das Lágrimas de São Pedro, pregado em Lisboa, no ano de 1669 , Vieira fala do olho como contendo dois canais. Um de dentro, que se abre com o registro do ver, outro canal que corre para fora e se solta com o registro do chorar. Pelos canais que correm para dentro, se o registro estiver aberto, o humano torna-se vulnerável às ilusões do mundo. Pelos canais que correm para fora, se os registros se soltam, saem as lágrimas.

Ora, como bem lembra Manoel Berlinck (2000), a paixão é sempre provocada pela presença ou imagem de algo que leva o indivíduo a reagir. Mais precisamente, o pathos, termo do qual derivam paixão e passividade, não nasce no corpo, ele brota no corpo, mas vem de longe e de fora. Assim, as manifestações do pathos são sinais de que o ser humano vive na dependência permanente do Outro.

Hervé Huot (1991) precisa que, no pensamento freudiano, o olho não é a fonte do desejo como o objeto sexual, nem seu instrumento ou seu representante (como o falo), mas é o órgão por meio do qual os objetos sexuais e o desejo ganham existência, sendo, portanto, a condição do desejo.

Edilene Queiroz (2005) ressalta que em todas as estruturas clínicas há sempre o aspecto traumático das imagens visuais. As imagens contaminam os sonhos e os pensamentos, fazendo o indivíduo sofrer. Em particular, ela frisa a importância das primeiras impressões visuais na vida psíquica do ser humano, antes mesmo de ser capaz de falar: "Se o olho é o órgão de apreensão da realidade, o olhar destaca-se como primeiro objeto de desejo e pode ser concebido como um primeiro objeto transicional do bebê na sua relação com a mãe" (p. 91). Retomando o pensamento de Lacan, do estádio do espelho ao estádio do véu, Queiroz conclui que a maneira de cada um experimentar a dança dos olhares determina um modo de funcionamento psíquico.

Entre silêncio e palavras, correm as lágrimas. Assim inicia Anne Vincent-Buffault (1988) sua história das lágrimas na França dos séculos XVIII e XIX. Este artigo, por sua vez, retoma discursos da antiga tradição

Rev. Latinoam. Psicopat. Fund., São Paulo, v. 13, n. 2, p. 283-295, junho 2010 
da medicina da alma da primeira modernidade, tais como sermões, tratados médicos e mesmo poemas, para examinar, a partir da noção de lágrimas, o que as relações entre o olhar e o chorar revelam sobre possibilidades de compreensão das relações entre pathos e logos. Em outras palavras, os discursos sobre as lágrimas serão um ponto de partida para reflexões sobre a vulnerabilidade do humano e a manifestação de suas paixões. Conclui-se que as lágrimas, como as palavras, enquanto representantes das paixões, ao mesmo tempo em que servem ao alívio e expressão dos movimentos da alma, são sempre faltosas, já que sempre meros representantes ou significantes, demandando interpretação.

\section{O olho e os olhares}

A teoria platônica da visão presume a projeção de um fogo interior que, junto à luz exterior, estende-se até o objeto. Seguindo esse pressuposto, o médico antigo Galeno (129?-199) afirma que o olho emite um "pneuma visual", convertendo o ar num instrumento óptico e iluminando o objeto da visão com o poder sensorial do olho. O olho impõe formas ao mundo visível, ele enxerga o mundo por meio de si mesmo, disseminando formas pela projeção desse chamado pneuma visual. Por outro lado, para Aristóteles, o olho é composto essencialmente de água, que assume as formas dos objetos que o estimula a ver. É uma matriz na qual a luz implanta sua substância, uma espécie de útero de luz que concebe o mundo em aceitação passiva de suas formas.

Sergei Lobanov-Rostovsky (1997) assinala que, sob a perspectiva platônica e galênica, o olho tem um papel ativo no processo da visão, enquanto que a teoria aristotélica da visão, ao rejeitar a ideia da emanação de um fogo espiritual, define o olho como um orifício vulnerável, um passivo receptor de luz. LobanovRostovsky mostra ainda que os estudos anatômicos do Renascimento, por meio da observação cada vez mais acurada do órgão da visão, colaboraram para a confirmação da teoria aristotélica do olho passivo, mas a teoria platônica do olho penetrante por meio do fogo subsiste nas metáforas do olhar, sobretudo no olhar fixo, atento ou pasmado. Durante a Renascença, o olho assiste à alma em sua tarefa de vigilância do corpo e do mundo. Em tempos de metáforas corporais políticas, o olho serve como vigia e juiz.

Como temos mostrado em outras ocasiões, mesmo os discursos médicos do período não prescindiam de analogias e metáforas que, atualmente, seriam taxadas de excessivamente poéticas pelos médicos, mas que, do ponto de vista psicanalítico, são de enorme interesse para a compreensão do corpo como efeito do imaginário e do imaginário como espelhamento do corpo. 


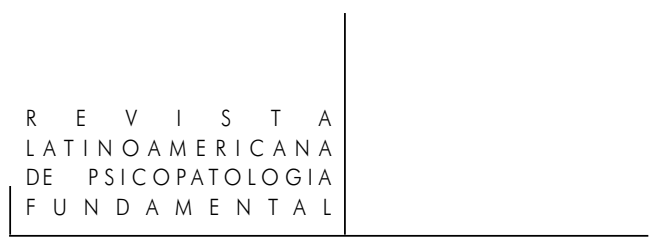

A poesia moderna foi marcada, entretanto, pela convenção, sagrada pelo grande poeta italiano Francesco Petrarca (1304-1374), de que os olhos masculinos são orifícios vulneráveis feridos pela beleza feminina. Lobanov-Rostovsky (1997) escreve que a urgência em domar o olhar feminino sustenta-se na ideia segundo a qual a beleza só pode trespassar o coração e fazer com que a paixão domine a alma, se atacar, antes de mais anda, os olhos, sua vítima passiva.

Esse lugar-comum também pode ser identificado na poesia lusitana. O olho e o olhar são temas recorrentes na lírica de Luís de Camões (1524/25?-1580). Aliás, na obra camoniana, a visão parece ser intensamente erotizada: a troca de olhares equivale, em muitos poemas, ao encontro entre o eu lírico e seu objeto de desejo; desse encontro de olhares seguem as paixões amorosas. Olhos também designam a própria dama, numa metonímia discreta e erótica ao mesmo tempo. O problema é que o encontro dos olhares pode ser dolorosamente faltoso. Assim, dos desencontros seguem outras paixões, menos deleitosas.

Portanto, pode-se concluir que os olhos ora são passivos receptores de impressões, ora desempenham a função ativa e penetrante. Enfim, o olhar do outro precisa ser visto para que atinja os olhos, ou como escreve o próprio poeta: "Vendo-vos, olhos sobejam;/ Não vos vendo, olhos não são" (Camões, 68(1598), 2005 , p. 491). Por sua vez, a projeção do olhar chega a ser tão aguda que pode ser comparado a uma pedrada, investida na qual a dama assume a posição de ataque, como em: "Uma dama, de malvada,/ Tomou seus olhos na mão/ E tirou-me uma pedrada/Com eles ao coração." O que não fica, porém, sem resposta, concretizando-se a (não) relação: "Armei minha funda então,/ E pus os meus olhos nela:/ Trape! quebro-lhe a janela" (Camões, 55, 2005, p. 480).

A importância do olhar como condição do desejo e, portanto, exposição ao pathos, permanece um tema recorrente na poesia do século de Vieira, como, por exemplo, no poema de Francisco de Vasconcelos (1665-1723), À valentia de uns olhos: "São Tisbe tão valentonas/Dos teus olhos as meninas,/Que metendo a saque as almas,/Põem fogo, e sangue as vidas,/(...) Por mais, que o peito se cubra/ Do respeito nas cortinas,/Não há defesa, que baste,/Nem parapeito, que sirva" (Vasconcelos, apud Pécora (Org.), 2002, p. 207).

Como já afirmado, o tema não se restringe à poesia e à retórica sagrada. $\mathrm{O}$ médico francês André Du Laurens (1558-1609) recapitula as principais teorias da visão: se o olho está pleno de chama, a visão se dá por emissão; se o mesmo compõe-se essencialmente de água ou humor cristalino, por recepção. A favor da teoria da recepção, conta justamente a teoria da paixão da alma: "Todo sentimento é uma paixão, e sentir não é outra coisa que padecer. Todo sentimento dá-se, portanto, por recepção" (Du Laurens, 1597, p. 53).

Vieira também compartilha da teoria de que, nos olhos, há essencialmente luz e água. Ele afirma que a vista por si mesma, quando desamparada da assistência 
da razão, conduz ao erro, ou como se dizia na época, ao engano. O olhar pode ser capturado por objetos que, na verdade, atualizam o desejo. Ou seja, os olhos estão sempre sujeitos à ilusão deformadora das paixões:

A paixão é a que erra, a paixão a que os engana, a paixão a que lhes perturba e troca as espécies, para que vejam uma coisa por outra. (...) Os olhos vêem pelo coração, e assim como quem vê por vidros de diversas cores, todas as coisas lhe parecem dáquella côr, assim as vistas se tingem dos mesmos humores, de que estão, bem ou mal, affectos os corações. (Vieira, 1669, v. IV, p. 111)

Todavia, ao mesmo tempo em que os olhos (e ele está se referindo aos olhos dos adultos), passivos e restritos ao sensível imediato, são o canal de entrada das imagos desencadeadoras do desejo, há também no indivíduo um caráter ativo, de cumplicidade, de disposição faltosa e desejante que toma as imagens como novos objetos das paixões, lançando-se num círculo vicioso.

Pécora (1993) explica que o olhar, segundo Vieira, procura imagens para o desejo. O olhar conferiria uma espécie de concretude ao que é apenas desejo e fantasia. O maior problema, do ponto de vista do catolicismo pregado por Vieira, é que o olhar tenderia a objetivar o engano ao materializar meras aparências e, sobretudo, a bastar-se nessa ilusão, o que é a essência da noção cristã do pecado. Sempre segundo Pécora, para Vieira, é a imagem passionalmente deformada de si mesmo que se quer ver o tempo todo: "O olhar não apenas imaginaria em si esse bem, como procuraria atribuir-lhe generalidade, universalidade, o que ele só pode fazer imaginando o próprio olhar do outro sobre si, imaginando-se a si próprio como a forma objetiva da admiração alheia (p. 309).

Lobanov-Rostovsky (1997) pontua que, para o médico Du Laurens, os olhos, plenos do humor cristalino, não são apenas defensivos, eles também são o mundo, ou melhor, eles criam um espetáculo interior, uma mimese do mundo que o cérebro toma como sendo a verdadeira imagem da realidade exterior. O que os olhos enviam ao cérebro é uma imagem de si mesmo.

\section{O pathos, o logos e as lágrimas}

As lágrimas eram consideradas, por muitos, a manifestação material mais primitiva (infantil) do pathos. Em sua monumental História natural (século I dzC.), citadíssima durante toda a Idade Média e mesmo Moderna, Plínio, o Velho, no Livro VII, afirma que o ser humano já nasce no suplício, chorando. Ele ressalta que o homem, sempre tão orgulhoso, nasce numa extrema fragilidade. Ele lembra que os animais possuem instintos que os guiam, enquanto os humanos não 
sabem nada antes que lhes ensinem: não sabem falar, andar, alimentar-se. A única coisa que o ser humano sabe fazer espontaneamente é chorar.

Essa manifestação tão primitiva era considerada irresistível. $\mathrm{Na}$ Consolação a minha mãe Helvia, Sêneca admite que a expressão dos afetos pode ser involuntária, pode trair os esforços de dominá-los, como é o caso das lágrimas surgidas quando se tenta calar a dor: "Nós procuramos às vezes oprimir e devorar nossos gemidos; mas, através da própria máscara que encobre nossos rostos, as lágrimas rebentam-se contra nossa vontade" (Sêneca, 1998, p. 68; trad. nossa).

Giuseppe Chiecchi (2005) pondera que o tema do choro era uma questão problemática e amplamente debatida na cultura clássica e na cristã, sobretudo, na tradição consolatória, para a qual assume importância capital.

Anne Vincent-Buffault (1988) aponta que nos romances franceses do século XVIII os personagens masculinos choram com volúpia inequívoca. Aliás, o sucesso de um romance podia ser medido pela quantidade de lágrimas vertidas por seus leitores. Vincent-Buffault defende que o pranto era uma manifestação emocional aceita e até valorizada socialmente, inclusive para os homens, ao longo dos séculos XVII e XVIII, tendo sido censurada pelos imperativos da boa conduta burguesa no século XIX.

Em específico, nos discursos médicos, filosóficos e morais do século XVII, as lágrimas podiam ser consideradas, ao mesmo tempo, sinal da tristeza sentida e remédio para a mesma, na medida em que consistem em um alívio natural das dores da alma.

Do ponto de vista da psicologia aristotélico-tomista, sustentar que haja alguma satisfação nas lágrimas ou mesmo efeitos consolatórios representa, porém, alguns problemas de ordem lógica, que foram tratados pelo próprio Tomás de Aquino (1228-1274) na parte dedicada às paixões da alma da Suma Teológica. As objeções levantadas por Tomás sobre as lágrimas aliviarem a tristeza incluem, em primeiro lugar, a ideia de que nenhum efeito pode diminuir sua causa e as lágrimas eram consideradas o efeito da tristeza. Entretanto, Tomás ratifica a afirmação de Agostinho, das Confissões, quando escreve que após a morte de seu melhor amigo só encontrava alívio nas lágrimas.

Conclui-se que as lágrimas e os gemidos aliviam naturalmente a tristeza. Em primeiro lugar, porque quando se fecha o que é nocivo no interior (nocivum interius clausum), ele aflige mais, por aumentar a concentração da alma. Quando se difunde para fora, a intenção da alma de alguma maneira se dispersa também e, assim, diminui a dor interior. Por isso, a tristeza é mitigada quando manifestada exteriormente pelo pranto, gemido ou pela palavra.

No entanto, as lágrimas não são apenas o efeito das tristezas. Em seu comentário ao Parva naturalia de Aristóteles, o filósofo conimbricense Manoel de Góis (1593) afirma que tanto uma forte dor quanto uma forte alegria podem cau- 
sar as lágrimas. É a paixão em seu caráter de excesso e transbordamento o que faz com que as lágrimas corram do interior para o exterior.

A coisa se complica ainda mais quando ocorrem as inversões, ou como questiona Vieira (1674): "Pois se a excessiva alegria é causa do pranto, a excessiva tristeza por que não será causa do riso?" (p. 117). Embora considere impróprio o riso da verdadeira dor, Vieira admite que para chorar não são precisos os olhos, ou seja, a natureza muniu o ser humano de diferentes formas de desafogo.

A controvérsia sobre a expressão ou a contensão das lágrimas parece ter sido importante o suficiente para fazer com que o pregador real português Pedro Calvo (m. 1551), escrevesse uma obra defendendo que as lágrimas são testemunhas naturais da dor interna: "Defesam das lagrimas dos iustos perseguidos e das sagradas religioens fruto das lagrimas de Christo. Para ele, bem sumariamente, as lágrimas, como as paixões, são manifestações naturais da condição humana: "naturalmente chorão com a vehemencia das dores, não por lagrimas serem doenças d'alma, mas sangue della, \& propriedades de nossa natureza" (Calvo, 1618, f. 97).

Em Vieira, o chorar não é apenas efeito do padecer, é também produto do

logos. É isso que ele afirma na disputa oratória sobre o riso de Demócrito e o choro de Heráclito que tanto impressionou a corte romana da rainha Cristina da Suécia. A própria questão já antecipa que se trataria de uma posição racional, mas, como solução da disputa, Vieira afirma que os dois filósofos lamentavam as fraquezas humanas, cada um a seu modo. Mesmo o riso de Demócrito nada mais consistiria do que em lágrimas de ironia ou ainda "lágrimas transformadas em riso por metamorfoses da dor" (Vieira, 1674, p. 117). Demócrito chorava as ignorâncias, Heráclito as misérias. De qualquer forma, as lágrimas seriam a resposta do logos à loucura do mundo.

\section{A fonte das lágrimas}

Florence Lévi (2003) afirma que há poucos estudos sobre as lágrimas do ponto de vista da filosofia, menos ainda na oratória de Vieira. Analisando o Sermão das Lágrimas de São Pedro, ela lembra que Vieira retoma um pensamento, recorrente desde a Antiguidade e a Idade Média, de que as lágrimas são o líquido da purificação: elas sinalizam a penitência ao mesmo tempo em que aliviam a dor e reanimam a alma. Além disso, as lágrimas, no limite, seriam de origem divina, por isso o cristão medieval pedia a Deus que voltasse seus olhos para ele e lhe 


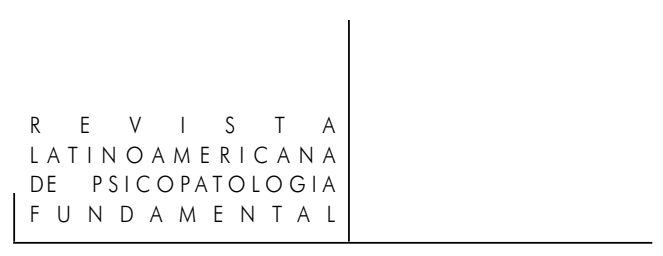

desse as lágrimas. De fato, no dito sermão, Vieira retoma a ideia segundo a qual as lágrimas derramadas por São Pedro tiveram nascimento nos olhos do Cristo.

Essa é uma imagem que reforça a importância da conversão como uma assunção da graça, do reconhecimento da condição de criatura, de saber e assumir que o princípio e o fim estão no Outro supremo, não em si. Entretanto, é nessa assunção que reside o vir a ser do homem convertido de Vieira, capaz de tomar uma decisão sobre seus próprios desejos. Afinal, para os jesuítas seiscentistas, o homem é sujeito da moral, isto é, atua livremente e pode aperfeiçoar-se para alcançar a felicidade. Acontece que, conforme o catolicismo pós-tridentino professado por esses mesmos jesuítas, razão e conversão equivalem-se.

Se pensarmos na importância das lágrimas na espiritualidade do fundador da Companhia, Inácio de Loyola (1491-1556), elas têm, de fato, o estatuto de sinal divino, mas jamais decisivo, e muito menos de dom sem uma formulação ativa de uma demanda via exercício espiritual. Roland Barthes (1971) analisa que o Diário espiritual (1544/1545), de Inácio de Loyola, é pautado pela contabilidade de manifestações supostamente divinas em seu corpo. Entre outras, alterações essencialmente sensoriais, que tocam o corpo fragmentado, como os movimentos de elevação, de tranqüilidade, de alegria, de calor, de luz e, acima de tudo, as próprias lágrimas, codificadas conforme o tempo da aparição e a quantidade. Entretanto, nenhuma dessas moções é decisiva. Apesar da clara demanda de uma resposta divina, referente a uma questão precisa da constituição da Ordem jesuítica, apesar da espera nem sempre paciente, da contabilidade obsessiva, do esforço interpretativo, há, no final, um respeito, uma aceitação reverencial do silêncio de Deus, da parte de Inácio, com ou sem olhos marejados. Pierre-Antoine Fabre (2007) mostra que esse Diário de moções interiores registra uma longa espera por um sinal, ao final da qual Inácio de Loyola autoriza-se por si mesmo, sempre diante de Deus, mas sempre só, na liberdade que o silêncio divino lhe obriga.

\section{Líquido nem tão transparente}

As lágrimas em si mesmas não passam de uma secreção aquosa. Elas dependem também das condições somáticas. O médico inglês Timothy Bright (1550?-1615), no seu Treatise of Melancholie, explica que o choro, grosso modo, dá-se por meio da contração do cérebro e movimento dos espíritos pressionando os líquidos para fora através dos olhos. O luto tem o poder de causar essa contração. Mas, por ser uma reação corporal, causas externas que não têm re- 
lação alguma com experiências afetivas também podem fazer com que as lágrimas sejam vertidas, como o vento ou a fumaça.

Mesmo quando provocadas pela paixão, não há, nelas mesmas, garantia certa de que se trata de um afeto genuíno ou de qual seja esse afeto. Já mencionamos que Vieira, junto com um sem-número de outros autores de sua época, admite que tanto a tristeza como a alegria podem causar as lágrimas.

Robert Burton (1577-1640), em sua análise da melancolia amorosa, parte do célebre Anatomia da melancolia, adverte que as lágrimas podem ser, inclusive, um artifício de sedução feminina. Burton não é, porém, o primeiro a escrever que uma mulher é capaz de chorar com um olho e rir com outro.

Vieira, por sua vez, é tão consciente de que as lágrimas ocorrem circunstancialmente, quanto do seu poder de persuasão. Retomando a Ars Amatoria de Ovídio, Vieira lembra que o agricultor rega as plantas para colher frutos, o impressor molha o papel para imprimir as letras e, do mesmo modo, deve fazer com as lágrimas quem pretende enternecer e abrandar corações. Ele afirma, então, que mais persuasivo teria sido se Demócrito, cujo gênio era jocoso, tivesse fingido lágrimas para provar sua indignação frente à ignorância humana: "Devia aproveitar-se da boca, não para rir, mas para umedecer os olhos e fingir as lágrimas" (Vieira, 1674, p. 131).

Os motivos, legítimos ou não, vêm de fora, mas, no fundo, chora-se sempre a si mesmo. O moralista francês La Rochefoucauld (1613-1680) é categórico ao afirmar que, sob o pretexto de chorar a perda de alguém querido, lamenta-se a diminuição do bem, do prazer e da consideração uma vez proporcionados pelo ausente. Lê-se entre suas conhecidas Máximas que: “(...) os mortos têm a honra de lágrimas que, em verdade, correm pelos vivos" (La Rochefoucauld, 1678, p. 65 ; trad. nossa).

\section{Das lágrimas às palavras}

Um lugar-comum, também muito aplicado nos discursos daquela época, refere-se às lágrimas como legítima linguagem da alma. Elas rompem do íntimo para dizer o que a boca calou. Por outro lado, retomando-se a pluralidade de interpretações a respeito do significado das lágrimas, pode-se afirmar que, se elas falam algo, no mínimo, elas são polissêmicas. Chora-se e fala-se sempre para alguém, mesmo que este não esteja presente ou visível e mantenha-se em silêncio. Tanto chorar, como falar alivia o peito. Chora-se de mentira, fala-se mentiras. Seriam, portanto, lágrimas e palavras intercambiáveis? 


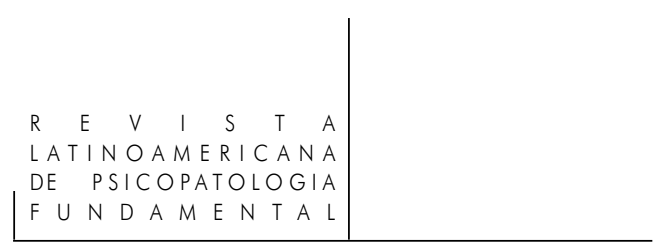

Para Vieira, porém, seguindo preceitos da antiga arte da retórica, há o tempo de chorar e o tempo de falar. No Sermão das Exéquias do Serenissimo Infante de Portugal Dom Duarte de Dolorosa memória, ele propõe substituir palavras por lágrimas, pois o chorar juntos realizaria as três ações da arte consolatória, isto é; sentir, louvar e, finalmente, consolar. As lágrimas também seriam mais eficientes do que o discurso porque esse se torna desordenado na experiência da dor: “(...) não me atrevo a prometer nem ordem, nem discurso, nem conserto, porque em semelhantes ocasiões a desordem do discurso, o desconcerto das palavras, o desasseio das razões é a harmonia da dor" (Vieira, 1649, p. 556).

Essa exortação às lágrimas restringe-se à primeira fase do sermão, dedicada a fazer compadecer pela morte do príncipe. Na segunda e maior parte do mesmo, na qual há o relato que compõe a memória de dom Duarte, as lágrimas deverão ser suspendidas e dar lugar ao discurso, nesse caso, tudo menos desorganizado, pois orientado fundamentalmente pelo logos.

No Sermão das Lágrimas de São Pedro, Vieira se pergunta porque dizem os evangelistas que São Pedro teria chorado lágrimas amargas. Se quisessem qualificar as lágrimas pela dor, teriam dito que chorou tristemente, sentidamente, lastimosamente ou irremediavelmente. Segundo Vieira, a amargura é qualidade da língua e não dos olhos. Assim, conclui o pregador que as lágrimas pagavam não apenas uma falta dos olhos, mas também uma falta da língua: o negar. A inspiração pode ser bíblica, mas, de toda forma, as lágrimas acabam sendo associadas à palavra.

Não é sem razão que, segundo a maioria desses discursos, as palavras advêm quando cessam as lágrimas. Antes de decidir a sua significação, é preciso interrogá-las. Por exemplo, para compreender a fundo o fenômeno das lágrimas, Timothy Bright recomenda que se examine, antes de mais nada, que tipo de coisa moveu ao choro, e, então, qual a causa que faz a paixão interna ser significada pelo doloroso gesto externo do chorar.

Se no princípio estava o olhar; no final, resta falar. Neste sentido, a clínica atual aproxima-se da medicina da alma. Sabemos que muitas lágrimas correm num divã: lágrimas de dores muito íntimas ou muito antigas que puderam finalmente fluir. Mas também lágrimas do além do princípio do prazer, tentativas de purificação via masoquismo moral, pedidos por uma significação decisiva, artifícios para esquivar-se da regra fundamental. Sabemos, igualmente, que o tempo da análise é o tempo da palavra. Mesmo que sejam palavras sobre as lágrimas.

\section{Referências}

Barthes, R. Sade, Fourier, Loyola. Paris: Seuil, 1971.

Rev. Latinoam. Psicopat. Fund., São Paulo, v. 13, n. 2, p. 283-295, junho 2010 
BRIGHT, T. A treatise of melancholy (...). London: John Windet, 1586.

Burton, R. The anatomy of melancholy: what it is, with all the kinds, causes, symptomes, prognostickes and severall cures of it (...).Oxford: Cripps, 1638.

Calvo, P. Defesam das lagrimas dos iustos perseguidos e das sagradas religioens fruto das lagrimas de Christo. Lisboa: Pedro Craesbecck, 1618.

CAmões, L. Obra Completa. Rio de Janeiro: Nova Aguilar: 2005.

ChIECCHI, G. La parola del dolore. Primi studi sulla letteratura consolatoria tra medioevo e umanesimo. Roma/Padova: Editrice Antenore, 2005.

Du Laurens, A. Discours de la conservation de la vue, des maladies melancholiques, des catarrhes, \& de la vieillesse. Paris: Jamet Mettayer, 1597.

FABRE, P.A. Introdução ao LoyolA, I. Journal des motions intérieures. Éditions critiques et nouvelle traduction des manuscrits autographes par Pierre-Antoine Fabre. Bruxelles: Éditions Lessius, 2007.

GoIs, M. Commentarii Conimbricensis Societatis Jesu, in Libros Aristotelis qui Parva Naturalia appellantur. Lisboa: Simão Lopes, 1593.

Huot, H. Do sujeito à imagem. Uma história do olho e Freud. Trad. de C. Berliner. São Paulo: Escuta, 1991.

La Rochefoucauld. Maximes et réflexions diverses. Paris: Garnier-Flammarion, 1977.

LÉvi, F. Voir ou pleurer. Les larmes du père António Vieira. Sigila. Revue transdisciplinaire franco-portugaise sur le secret, v. 12, p. 35-49, 2003.

Lobanov-Rostovsky, S. Taming the Basilisk. In: Hillman, D.; Mazzio, C. (Orgs.). The body in parts: fantasies of corporeality in early modern Europe. New York/London: Routledge, 1997. p. 195-217.

Pécora, A. O demônio mudo. In: Novaes, A. (Org.). O olhar. São Paulo: Companhia das Letras, 1993. p. 301-316.

Pécora, A. (Org.). Poesia Seiscentista. São Paulo: Hedra, 2002.

PLínIO. Histoire Naturelle de Pline. Trad. de E. Littré. Paris: Firmin-Didot, 1883.

QueIROZ, E. F. A trama do olhar. Latin-American Journal of Fundamental Psychopathology on Line, São Paulo, v. 1, p. 89-100, nov. 2005.

SÊNECA. Entretiens. Lettres a Lucilius. Introdução e tradução de Paul Veyne. Paris: Robert Lafond, 1998.

TomÁs de Aquino. Suma Teológica. Edição bilíngue. São Paulo: Loyola, 2003.

VieIRA, A. (1649). Sermões. Org. de A. Pécora. São Paulo: Hedra, 2001. . (1669). Sermões. Porto: Lello e Irmão, 1951. v. IV. 


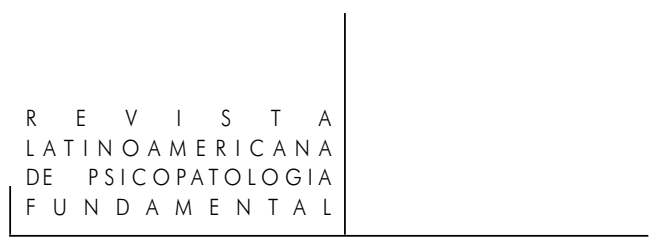

. (1674). As lágrimas de Heráclito. Org. de S.N. SALOMão. São Paulo: Editora

34, 2001.

VIncent-Buffault, A. História das lágrimas: séculos XVIII e XIX. Tradução brasileira de L. Marques e M. Gambini. Rio de Janeiro: Paz e Terra, 1988.

\section{Resumos}

(From tears to words: manifestations of pathos according to modern medicine of the soul )

This article analyses early modern texts on the sources, nature and reason for tears. The notion of the gaze is first discussed in order to investigate the origin of the passions. Next, the relationships between weeping and affectivity is taken up, and then the relationships between tears and words.

Key words: Tears, pathos, words, medicine of the soul

(Des larmes aux mots: manifestations du pathos selon la médecine de l'âme moderne)

Cet article analyse une sélection de discours de la première modernité sur les larmes, leurs origines, leur nature et leur finalité. Nous analysons d'abord la notion $d u$ regard pour aboutir à l'origine des passions de l'âme et examinons ensuite les rapports entre l'acte de pleurer et l'affectivité, pour finalement discuter les rapports entre les larmes et les paroles.

Mots clés: Larmes, pathos, parole, médecine de l'âme

(De las lágrimas a las palabras: manifestaciones del pathos segun la medicina del alma moderna)

Este artículo se propone analizar discursos de la primera modernidad sobre la fuente, naturaleza y finalidad de las lágrimas. En primer lugar, examina la noción de mirar para llegar al origen de las pasiones. Después, se abordan las relaciones entre llorar y la afectividad, para, finalmente, discutir la relación de las lágrimas y las palabras.

Palabras claves: Lágrimas, pathos, palabras, medicina del alma.

Citação/Citation: Carvalho da Silva, P.J.; Cavalcante, M.B.R. Das lágrimas às palavras: manifestações do pathos segundo a medicina da alma moderna. Revista Latinoamericana de Psicopatologia Fundamental, São Paulo, v. 13, n. 2, p. 283-295, jun. 2010.

Rev. Latinoam. Psicopat. Fund., São Paulo, v. 13, n. 2, p. 283-295, junho 2010 


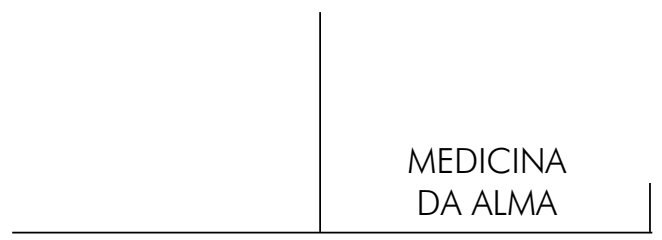

Editor do artigo/Editor: Prof. Dr. Paulo José Carvalho da Silva

Recebido/Received: 20.4.2010 / 4.20.2010 Aceito/Accepted: 30.4.2010 / 4.30.2010

Copyright: (C) 2009 Associação Universitária de Pesquisa em Psicopatologia Fundamental/ University Association for Research in Fundamental Psychopathology. Este é um artigo de livre acesso, que permite uso irrestrito, distribuição e reprodução em qualquer meio, desde que $\mathrm{o}$ autor e a fonte sejam citados/This is an open-access article, which permits unrestricted use, distribution, and reproduction in any medium, provided the original author and source are credited.

Financiamento/Funding: Esta pesquisa foi financiada pela Fundação de Apoio à Pesquisa do Estado de São Paulo - Fapesp /This research has been funded by the Fondation for Research Support of the State of Sao Paulo.

Conflito de interesses/Conflict of interest: Os autores declaram que não há conflito de interesses/The authors declare that has no conflict of interest.

\section{Paulo José Carvalho da Silva}

Psicólogo; psicanalista; mestre em História da Ciência pela Pontifícia Universidade Católica de São Paulo - PUC-SP (São Paulo, SP, Brasil); doutor em Psicologia pela Universidade de São Paulo - USP (Ribeirão Preto, SP, Brasil); professor doutor da Faculdade de Psicologia da Pontifícia Universidade Católica de São Paulo - PUC-SP; membro da Associação Universitária de Pesquisa em Psicopatologia Fundamental (São Paulo, SP, Brasil).

Rua Cajaíba, 15

05025-000 São Paulo, SP, Brasil

Fone: (11) 9248-9202

e-mail: paulojcs@hotmail.com

\section{Melina Borges Rosa Cavalcante}

Graduanda em Psicologia pela Pontifícia Universidade Católica de São Paulo - PUCSP (São Paulo, SP, Brasil), realizou pesquisa em Iniciação Científica sob orientação do prof. dr. Paulo José Carvalho da Silva, com bolsa PIBIC/CEPE, sobre as lágrimas em sermões do padre Antônio Vieira.

Rua prof. Gioconda Mussolini, 291/43 - Butantã

05587-120 São Paulo, SP

e-mail: melina_brc@hotmail.com 